\title{
One Dose of a Novel Vaccine Containing Two Genotypes of Porcine Circovirus (PCV2a and PCV2b) and Mycoplasma hyopneumoniae Conferred a Duration of Immunity of 23 Weeks
}

\author{
José Carlos Mancera Gracia ${ }^{1, *}$, Megan Smutzer ${ }^{2}$, Lucas Taylor ${ }^{2}$, Mónica Balasch ${ }^{3}$ and Meggan Bandrick ${ }^{2}$ \\ 1 Zoetis Belgium S.A., Mercuriusstraat 20, 1930 Zaventem, Belgium \\ 2 Zoetis Inc., Veterinary Medicine Research and Development, 333 Portage St., Kalamazoo, MI 49007, USA; \\ megan.smutzer@zoetis.com (M.S.); lucas.p.taylor@zoetis.com (L.T.); meggan.bandrick@zoetis.com (M.B.) \\ 3 Zoetis Manufacturing \& Research Spain S.L., Ctra. Camprodon s/n, Finca La Riba, 17813 Vall de Bianya, \\ Spain; monica.balasch@zoetis.com \\ * Correspondence: pepe.mancera@zoetis.com; Tel.: +32-2-746-8060
}

\section{check for} updates

Citation: Mancera Gracia, J.C.; Smutzer, M.; Taylor, L.; Balasch, M.; Bandrick, M. One Dose of a Novel Vaccine Containing Two Genotypes of Porcine Circovirus (PCV2a and PCV2b) and Mycoplasma hyopneumoniae Conferred a Duration of Immunity of 23 Weeks. Vaccines 2021, 9, 834. https://doi.org/ $10.3390 /$ vaccines 9080834

Academic Editor: Romain Paillot

Received: 14 June 2021

Accepted: 23 July 2021

Published: 29 July 2021

Publisher's Note: MDPI stays neutral with regard to jurisdictional claims in published maps and institutional affiliations.

Copyright: (c) 2021 by the authors. Licensee MDPI, Basel, Switzerland. This article is an open access article distributed under the terms and conditions of the Creative Commons Attribution (CC BY) license (https:/ / creativecommons.org/licenses/by/ $4.0 /)$.

\begin{abstract}
Porcine circovirus type 2 (PCV2) and Mycoplasma hyopneumoniae (Mhyo) are important swine pathogens for which vaccination is a key control strategy. Three separate studies were performed to evaluate the duration of immunity (DOI) conferred by a novel vaccine combining PCV2a/PCV2b and Mhyo into a ready-to-use formulation. In each study, three-week-old naïve piglets were vaccinated (Day 0) and challenged 23-weeks later (Day 159) with either PCV2a, PCV2b or Mhyo. Pigs were euthanized three-to-four-weeks post-challenge. Vaccinated pigs had significantly lower PCV2 viremia from Day 168 until Day 175 (PCV2a study) or until euthanasia (PCV2b study), respectively. Fecal shedding was significantly lower for PCV2a-challenged from Day 171 until Day 178, and for PCV2b-challenged from Day 172 until euthanasia. In the PCV2a challenge study, there were no differences among vaccinates and controls in terms of percent of pigs positive for PCV2 immunohistochemistry, histiocytic replacement, or lymphoid depletion. However, significant differences for immunohistochemistry and histiocytic replacement, not lymphoid depletion, were observed among vaccinates and controls following PCV2b challenge. Vaccination supposed a significant reduction in the mean percentage of Mhyo-like lesions in the lung. Percentages of lung tissues positive for Mhyo via immunohistochemistry were $49.3 \%$ and $67.1 \%$ for vaccinated and control groups, respectively. One dose of the novel PCV2a/PCV2b/Mhyo vaccine conferred robust protection against challenge 23-weeks later for all three fractions.
\end{abstract}

Keywords: swine; porcine circovirus 2; Mycoplasma hyopneumoniae; vaccine; duration of immunity

\section{Introduction}

The Porcine Respiratory Disease Complex (PRDC) is a disease of swine caused by a combination of viral (porcine circovirus type 2 (PCV2), porcine reproductive and respiratory syndrome virus (PRRSV), pseudorabies virus (PRV), swine influenza virus (SIV)), bacterial (Actinobacillus pleuropneumoniae, Bordetella bronchiseptica, Mycoplasma hyopneumoniae (Mhyo), Pasteurella multocida, ... ) and adverse management conditions (overcrowding, poor ventilation, temperature, ... ). PRDC main clinical manifestations are coughing, dyspnea, poor growth, and increased mortality. This syndrome can result in significant economic loses to the swine industry due to medication expenses, increased mortality, and the failure to gain weight during the end of the fattening period [1]. PCV2 and Mhyo are accounted as two of the most significant pathogens involved in the PRDC.

PCV2 is a single-stranded nonenveloped DNA virus, which has been described as the etiological agent of post-weaning multi-systemic wasting disease syndrome (PMWS) in the 1990s. PCV2 was later related to other clinical manifestations such as the already mentioned Porcine Respiratory Disease Complex (PRDC) or the Porcine Dermatitis and 
Nephropathy Syndrome. All those clinical manifestations are known as PCV2-associated diseases (PCVAD) and mainly cause disease in pigs around 5 to 18 weeks old. The primary transmission route of PCV2 is by oronasal exposure and the virus has been isolated in most pig secretions such as nasal and ocular secretions, feces, saliva, or urine [2,3]. Due to their single stranded DNA nature and small genomic size, PCV2 viruses have a very high evolutionary rate. In fact, PCV2 viruses have a mutation frequency of around $10^{3}-10^{4}$ substitutions/site/year, which is one of the highest rates among DNA viruses and it is at the level of the variation seen in RNA viruses [4]. This high mutation rate, together with the high rate of recombination (second to PCV2's propensity for multi-strain or multi-genotype co-infections and infection persistence), immune pressure lead to the genesis of novel and divergent PCV2 variants. These various mechanisms of evolution explain that until today up to eight different genotypes, including two recombinant ones have been described (PCV2ah) $[5,6]$. Those genotypes were proposed based a maximum intra-genotype $p$-distance $13 \%$ (based on the ORF2 gene, which encodes the capsid protein) [6]. This information gives an idea on the complexity and the divergent scenario posed by PCV2 virus. However, although eight different genotypes were described nowadays there is a co-existence of three main PCV2 genotypes which are persistently causing disease in the field [7]. The first genotype identified was PCV2a, which was dominant until the early 2000s [8]. Since then, PCV2b was isolated and became predominant in commercial swine populations; PCV2b was related with more severe PCVAD clinical manifestations [9-13]. Finally, in 2011 PCV2d emerged as an evolution of PCV2b and took over as the predominant genotype worldwide [14,15]. Mhyo causes the enzootic pneumonia in pigs. Enzootic pneumonia is a respiratory syndrome that poses a great economic burden to swine production all around the world. Mhyo primarily infects ciliated epithelial cells on the surface of bronchioles, bronchi, and trachea causing cilia and epithelial cell damage. Although Mhyo affects pigs of all ages, clinical signs are mostly apparent in growing and finishing pigs. As a major contributor to PRDC Mhyo is routinely identified as concomitant agent with other infectious agents such as PRRSV or PCV2. As a strict respiratory pathogen Mhyo can be found in nasal secretions of diseased pigs. Therefore, transmission occurs via direct, nose-to-nose, contact [16,17]. In consequence, due to the threat posed by both pathogens (PCV2 and Mhyo) their prevention and control are crucial steps to successfully manage PRDC, even when other infectious and non-infectious factors are present [18].

Vaccination is one of the principal strategies to decrease the impact of PCV2 and Mhyo in the field. PCV2 vaccines are usually applied to piglets as a single dose around week 3 of age and aim to prevent PCV2 effects post weaning. Despite circulation of different PCV2 genotypes, most commercial vaccines worldwide still target PCV2a only $[19,20]$. Although PCV2a vaccines generate neutralizing antibodies that cross-react and are efficacious in avoiding clinical disease produced by heterologous strains, there are concerns about their ability to prevent viral replication or transmission [21,22]. As a consequence, there is an increasing deliberation around update of PCV2 vaccines in order to increase vaccine efficacy [20]. Mhyo commercial vaccines are mostly applied to piglets as a single dose between the first and the third weeks of age and aim to prevent the effects of Mhyo occurring after weaning [23]. As a consequence, due to the parallelisms seen on both infections and that vaccination of both pathogens takes place in piglets around the same age, combined vaccination has been explored since 2010 [24].

One of the variables that characterizes the efficacy of a vaccine is the duration of immunity (DOI). The DOI of a vaccine determines at least how long after vaccination a vaccine can confer robust protection. With the aim of assessing the DOI conferred by one dose of a novel vaccine combining PCV2a/PCV2b and Mhyo, three separate studies were performed. In each independent study three-week-old piglets naïve to PCV2 or Mhyo were vaccinated once and challenged 23 weeks later with either PCV2a, PCV2b, or Mhyo. Inmunological, virological/bacterial, and clinical variables were considered to measure the protective efficacy of the vaccine after the experimental challenge. 


\section{Materials and Methods}

\subsection{Study Design}

One independent study was completed to evaluate the duration of immunity generated by each of the three different components of the vaccine: PCV2 genotype a, PCV2 genotype $b$, and Mhyo. All independent studies and groups present in this manuscript are summarized in Table 1.

Table 1. Independent studies, treatment groups, and vaccination and challenge patterns involved in this experiment.

\begin{tabular}{ccccc}
\hline Study Number & Treatment & $\begin{array}{c}\text { Number of } \\
\text { Animals }\end{array}$ & Vaccine & Challenge \\
\hline Study 1 & T01 & 30 & $\begin{array}{c}\text { Mhyo fraction } \\
\text { PCV2a, PCV2b } \\
\text { and Mhyo fractions }\end{array}$ & PCV2a \\
\hline Study 2 & T03 & 31 & $\begin{array}{c}\text { Mhyo fraction } \\
\text { PCV2a, PCV2b } \\
\text { and Mhyo fractions }\end{array}$ & PCV2b \\
\hline Ttudy 3 & T04 & 30 & $\begin{array}{c}\text { Not vaccinated } \\
\text { PCV2a and PCV2b } \\
\text { fractions } \\
\text { PCV2a, PCV2b }\end{array}$ & Not challenged \\
& T06 & 10 & 71 & Mhyo \\
\end{tabular}

Study 1 evaluated the duration of immunity of the PCV2a fraction of the vaccine. Sixtyone piglets seronegative for PCV2 antibodies (by indirect ELISA) and without detectable PCV2 DNA (RT-qPCR) in blood were selected. Thirty pigs were randomly allotted to the control group vaccinated only with the Mhyo fraction of the vaccine (T01). The remaining thirty-one animals were enrolled in the vaccinated group, vaccinated with the complete vaccine containing the PCV2a, PCV2b, and Mhyo fractions (T02). Study 2 evaluated the duration of immunity of the PCV2b fraction of the vaccine. Sixty piglets also seronegative for PCV2 antibodies and without detectable PCV2 DNA in blood were selected. Thirty were randomly allotted to the control group vaccinated with the Mhyo fraction only (T03) and the remaining thirty were enrolled to the vaccinated group, containing the complete vaccine (T04). Finally, study 3 aimed to evaluate the duration of immunity of the vaccine's Mhyo fraction. One hundred and fifty-two piglets seronegative for Mhyo antibodies were selected. Ten piglets were randomly allotted to the non-vaccinated control group (T05) and were used to evaluate the health of the animals prior to Mhyo challenge; seventy-one animals were allotted to the vaccine control group and were vaccinated only with the PCV2a and PCV2b fractions (T06). Finally, the remaining seventy-one pigs were enrolled to the vaccinated group and were vaccinated with all three fractions (T07).

Pigs were vaccinated around the third week of age with the complete vaccine (T02, T04, and T07). Animals from PCV2 control groups (T01 and T03) received a $2 \mathrm{~mL}$ dose of the mentioned knockout placebo containing only Mhyo bacterin via the intramuscular route. On the other hand, animals from Mhyo control group (T06) received $2 \mathrm{~mL}$ intramuscular dose of the mentioned knockout placebo containing PCV2a and PCV2b fractions, animals from the non-vaccinated control group (T05) did not receive any vaccine product. Twentythree weeks after vaccination all animals (with the exception of T05) were challenged with the correspondent pathogen as specified in the challenge section. Euthanasia and necropsy occurred 3 to 4 weeks after challenge. In studies 1 and 2, serum was collected for evaluation of PCV2-specific antibodies and PCV2 viremia. Fecal swabs were collected for evaluation of PCV2 shedding. At necropsy lymphoid tissues (inguinal/mesenteric/tracheobronchial lymph nodes and tonsil) were collected for microscopic examination of lesions characteristic of PCV2 disease and PCV2 colonization via immunohistochemistry. In study 3, serum and body weights were collected for evaluation of Mhyo-specific antibodies and the impact of the vaccination in the body weight gain, respectively. At necropsy, lungs were scored for 
macroscopic lesions consistent with Mhyo-pneumonia and lung tissue was collected for pathological evaluation.

Treatments, housing, husbandry, and euthanasia methods in all groups were aligned with the European Union Guidelines and Good Clinical Practices. Animals were housed and managed following the guidelines depicted in the Guide for the Care and Use of Laboratory Animals of the National Institutes of Health. During the vaccination phase of study 1 all animals were randomly housed in one single room containing 6 different pens. Prior to challenge, animals were moved into a BSL-2 facility that consisted in 3 rooms with 2 independent pens per room ( 10 animals per pen). During study 3, pigs were randomly allocated in 1 facility containing four independent pens. In all three studies animals were kept with the same pen mates throughout the study. Piglets within litters were kept together whenever possible throughout the study. Housing during study 2 mimicked that of study 1 . All study protocols were approved by the Zoetis Institutional Animal Care and Use Committee, with the following reference numbers: studies 1 and 2, \# KZ-3087e-2014-10-tkh; and study 3, 17-NARDO-04. Stocking density followed the Site SOPs, and the FASS Consortium Guide for Care and Use of Agricultural Animals in Research and Teaching, 3rd Edition, 2010.

\subsection{Vaccination}

Piglets were between 18 and 25 days-old at vaccination. One intramuscular dose of 2 $\mathrm{mL}$ of a trivalent vaccine containing PCV1-2a Chimera, PCV1-2b Chimera, both killed whole viruses, Mhyo bacterin, and 10\% SP Oil adjuvant was administered into the right neck to T02, T04, and T07. Piglets from T01, T03, and T06 received one intramuscular dose of $2 \mathrm{~mL}$ into the right neck of a knock-out vaccine containing PCV2a and PCV2b or Mhyo and 10\% SP Oil adjuvant, respectively. Piglets from T05 did not receive any vaccine.

\subsection{Challenge}

Twenty-three weeks post-vaccination all pigs were challenged. Piglets from study 1 were inoculated with a total of $4 \mathrm{~mL}$ of a PCV2a field strain (isolate 40895) containing approximately $10^{6} \mathrm{TCID}_{50}$ per dose. Two $\mathrm{mL}$ were administered intramuscularly, and the remaining $2 \mathrm{~mL}$ were administered intranasally ( $1 \mathrm{~mL}$ per nostril). In study 2, all piglets were inoculated using the same procedures and route described for study 1 but using a PCV2b strain (isolate Fd7) containing approximately $10^{6.2} \mathrm{TCID}_{50}$ per dose. In study 3, all piglets were inoculated with $20 \mathrm{~mL}$ of the Mhyo 232 strain diluted 1:1000 in Friis Medium and administered intratracheally. For the intratracheal challenge pigs were manually restrained by a qualified technician and a speculum was used to hold the mouth open. A catheter was manually placed into the trachea; once correct placement of the catheter was confirmed, the challenge material was injected via syringe followed by a small volume of air to clear the catheter. A separate catheter was used for each pig.

\subsection{Clinical Observations}

Before vaccination all pigs were evaluated to ensure that only clinically healthy pigs were enrolled in the study. Around $1 \mathrm{~h}$ after vaccination and post challenge abnormal clinical signs all, such as depression, increased respiration, vomiting and lameness were evaluated in all animals. In addition, general health observations were done every day in the three studies.

\subsection{PCV2 Real-Time Quantitative PCR}

A commercial kit (QiaAmp Blood 96 kit, Qiagen, Valencia, CA) was used to extract the DNA from serum and fecal swab samples collected on Day $0,159,164 / 165,168,171 / 172$, $175,178 / 179$, and 181 in studies 1 and 2 . A real-time quantitative PCR (qPCR) was used for the quantification of PCV2 genome. The program was done taking five microliter of DNA as template and consisted on a reverse transcription of $2 \mathrm{~min}$ at $50{ }^{\circ} \mathrm{C}$, a denaturion phase of $10 \mathrm{~min}$ at $95^{\circ} \mathrm{C}$, and a total of 40 cycles, each cycle consisted of $25 \mathrm{~s}$ at $95^{\circ} \mathrm{C}$ for 
denaturation and $1 \mathrm{~min}$ at $60^{\circ} \mathrm{C}$ for annealing/extension. The process was performed using a thermocycler (Bio-Rad CFX 96). The following primers and probe sequences were used:

- $\quad$ Forward primer (P1591F), 5' TGG CCC GCA GTA TTT GAT T 3' (Final concentration $5 \mu \mathrm{M})$;

- Reverse primer (P1642R), 5' CAG CTG GCA CAG CAG TTG AG 3' (Final concentration $5 \mu \mathrm{M})$;

- Probe (P1591Probe), 5’ FAM-CCA GCA ATC/ZEN/AGA CCC CGT TGG AAT GIABkFQ 3' (Final concentration $10 \mu \mathrm{M}$ ).

All reactions with test samples were done in duplicate. In addition, a standard curve was generated by performing three replicates for each of the six progressive 1:10 dilutions of a seminal standard containing a known number of copies. Finally, to quantify the amount of virus, the quantity of DNA copies found on a $5 \mu \mathrm{L}$ reaction were multiplied $\mathrm{x}$ 200 to obtain the number of copies $/ \mathrm{mL}$.

\subsection{PCV2 Pathological Studies}

At necropsy samples from tonsil and lymph nodes (inguinal, mesenteric, and tracheobronchial) were taken from all pigs involved in studies 1 and 2 and fixed by immersion in $10 \%$ buffered formalin. Later, samples were dehydrated and embedded in paraffin wax to ensure the preservation of tissue structure. Then, all samples were sent to the Iowa State University Veterinary Diagnostic Laboratory for histopathological analysis and for PCV2-antigen detection by immunohistochemistry (IHC). The histopathological examination was performed on $4 \mu \mathrm{m}$ thick sections stained with hematoxylin and eosin. A blinded evaluation was performed by giving a subjective score for severity, from 0 (none) to 3 (severe), of lymphoid depletion (LD) and histiocytic replacement (HR). An animal was considered to have lesions if one or more tissues had a value over 0 and the final result was recorded as Yes (+) or No (-).

IHC was performed on the mentioned tissues by using a rabbit polyclonal antiserum against PCV2, following a previously defined protocol [25]. The quantity of PCV2 antigen found in the mentioned tissues were recorded as 0 (no staining) and 1-3 (different levels of staining). A score of 0 was considered negative while a score equal or higher to 1 was considered as positive.

\subsection{Mhyo Pathological Studies}

In study 3, half of the non-vaccinated control animals (T05) were necropsied approximately 12 weeks after vaccination. The remaining non-vaccinated control pigs were necropsied on the challenge day, prior to challenge. Four weeks after challenge all pigs were necropsied. Each pig was anesthetized, exsanguinated and necropsied. At necropsy Mhyo macroscopic lesions in the lungs were evaluated on a range from $0 \%$ to $100 \%$ for consolidation for each lobe (left cranial, left middle, left caudal, right cranial, right middle, right caudal, and accessory) by a veterinarian. A representative section of lung tissue was dissected from each animal, fixed in $10 \%$ buffered formalin solution and evaluated for positive or negative Mhyo status via IHC at the UMN-VDL. A labeled streptavidin-biotin detection kit (DAKO) was used on paraffin-embedded tissue sections to detect the presence of Mhyo. Before applying the Mhyo monoclonal antibody (identification number D79DI-7; Richard Ross, Iowa State University) samples were dewaxed and rehydrated, covered with 1:10 ethylenediaminetetraacetic acid butter solution, $\mathrm{pH}$ 6.0 (Richard Allan Scientific, Kalamazoo, MI, USA), boiled for $5 \mathrm{~min}$ and after cooling for $20 \mathrm{~min}$, the slides were rinsed. Then the mentioned antibody was applied for $2 \mathrm{~h}$ at room temperature in a 1:500 dilution. Later, the detection kit (DAKO) was used. Stained slides were scored on the following way: 0 , no signal detectable; 1 , weak labeling lining the ciliated epithelium of at least one airway; 2 , weak-to-moderate labeling on the surface of a low number of airways and 3 , intense labeling on the surface of several airways. 


\subsection{Serology}

The existence of antibodies against PCV2 in serum samples obtained throughout studies 1 and 2 was evaluated using an indirect ELISA test. Briefly, positive capture antigen (Sf9 cells infected with recombinant baculovirus expressing PCV2 capsid protein) was used to coat 96-well polystyrene plates. Some other wells were coated with conventional Sf9 cells to act as a negative control. Later, the plates were treated with blocking reagent and incubated with sera from test samples. A sample know to be positive for PCV2 antibodies was added to wells containing positive capture antigen as well as to wells coated with negative capture antigen to act as a positive control. The secondary antibody, a goat antiswine antibody conjugated with HRP, was then added. Finally, the peroxidase substrate (TMB) was pipetted and incubated for $20 \pm 2 \mathrm{~min}$. The color generated was quantified by an ELISA plate reader. Each reagent added to the immuno-plates was incubated according to protocol and was ringed to remove the excess reagent before to each step. The OD value of positive control and test samples was calculated by subtracting average OD of negative control from average OD of test samples and positive control. Serum antibody value was expressed as S/P (sample/positive control) ratio, which is the OD of the test sample divided by that of the positive control sample.

Serum samples obtained from study 3 were analyzed by the University of Minnesota, Veterinary Diagnostic Laboratory (UMN-VDL). An ELISA blocking assay (Dako Corporation, Carpenteria, CA, USA) was used to detect the existence of Mhyo antibodies. Briefly, Mhyo antigen was used to coat the 96 -well plates on which serum samples were incubated. Peroxidase conjugated mouse monoclonal antibody to Mhyo was pipetted to the plates. The conjugated antibody competed with any Mhyo antibody present in the sample serum for binding siters on the immobilized antigen. After $15 \mathrm{~min}$ of incubation, wells were ringed and the substrate was added. The color reaction was halted by the action of the acid. The intensity of color in measured at $450 \mathrm{~nm}$ and compared with the absorbance of buffer controls. Samples with a mean OD value lower than $50 \%$ of the OD obtained from buffer control were considered as positive.

\subsection{Statistical Analysis}

A centralized data management system (SAS/STAT User's Version 9.4, or higher, SAS Institute, Cary, NC, USA) was used to perform all data summaries and analyses. An appropriate logarithm transformation was applied to the results before performing the statistical analysis, if necessary.

Frequency distribution of PCV2 viremia, PCV2 fecal shedding, microscopic lesions, and IHC scores were calculated per treatment and time point data were collected. Animals that were viremic or shed at any time in the study (ever viremic or ever shed) were analyzed with a generalized linear repeated measures mixed model with fixed effect treatment and random effects room, pen with room, and block within pen and room. If the treatment main effect was significant $(p \leq 0.05)$, pair-wise treatment comparisons were made. If the mixed model did not converge, Fisher's Exact test was used for analysis.

The stratified prevented fraction was used to summarize if the animal ever shed PCV2 or had any abnormal LD, HR, or IHC results with $95 \%$ confidence intervals.

Viremia, viral load in feces, and PCV2 serology data were analyzed with a generalized linear repeated measures mixed model with fixed effect treatment, time point, and treatment by time point interaction and random effects room, pen with room and block within pen and room, and animal within pen, room, block, and treatment (which is the animal term). Comparisons between treatments were made at each time point. A $5 \%$ level of significance $(p \leq 0.05)$ was applied to evaluate the statistical differences. Least squares means (back transformed for viremia, viral load in fecal shedding and serology), standard errors, $95 \%$ confidence intervals of means and ranges were calculated per treatment and time point. Serology means prior to vaccination (Day 0 or Day -1 ) were not model based.

Percentage of total lung lesions consistent with Mhyo infections was estimated using the subsequent method: Percentage of total lung with lesions $=\{(0.10 \times$ left cranial $)+$ 
$(0.10 \times$ left middle $)+(0.25 \times$ left caudal $)+(0.10 \times$ right cranial $)+(0.10 \times$ right middle $)+$ $(0.25 \times$ right caudal $)+(0.10 \times$ accessory $)\}$ [26]. The arcsine square root transformation was applied to the percentage of total lung with lesions before the analysis. A general linear mixed model with fixed term treatment random terms: pen, and block within pen was used to calculate the percentage of Total Lung with Lesions. When a significant treatment effect was found, pair-wise comparisons were made between treatment groups. Back transformed least squares means of percentage of total lung with lesions, and their 95\% confidence intervals were calculated as well as the minimums and maximums.

Frequency distributions were calculated for each treatment groups considering the next: $0 \%$ to $<5 \%, 5 \%$ to $<10 \%, 10 \%$ to $<20 \%, 20 \%$ to $<30 \%, 30 \%$ and greater.

Mhyo serology results were log transformed prior to analysis and a general linear mixed model with repeated measured with fixed effects: treatment, time point and treatment by time point interaction and random effects: pen, block within pen, and animal within block, pen, treatment, which is the animal term, was used for the analysis. After testing for a significant $(p \leq 0.05)$ treatment effect or treatment by time-point interaction linear combinations of the parameter estimates were used in a priori contrasts.

Body weights were examined using a general linear repeated measures mixed model with fixed effects: treatment, time point, and treatment and time point interaction and random effects: pen, block within pen, and animal within pen, block, and treatment (which is the animal term). Treatment least squares means, $95 \%$ confidence intervals, the minimum and maximum were calculated for each time point data are collected. If the treatment effect or treatment by time point interaction was significant, pair-wise treatment comparisons were made between groups.

\section{Results}

\subsection{PCV2 Viremia}

The results of PCV2 viremia observed in studies 1 and 2 are summarized in Figure 1 and Table 2. All pigs were negative to PCV2 presence in blood before challenge (Day 159). On study 1, PCV2a viremia was initially detected four days after challenge (Day 164) in control group only. From Day 168 through Day 175, mean viremia in the vaccinated pigs (T02) was significantly inferior $(p \leq 0.0011)$ than that of the control group (T01). The percentage of pigs that showed viremia at any point of the study was also significantly lower $(p=0.0001)$ in vaccinated group (T02) to that in control pigs (T01). A clinically relevant prevented fraction, with a lower $95 \%$ interval $>0$, was also demonstrated.

On study 2, PCV2b viremia was initially detected five days after challenge (Day 165). Viremia was significantly lower $(p \leq 0.0029)$ in the vaccinated group (T04) from Day 168 until study completion (Day 181), when compared to controls (T03). The percentage of pigs with viremia at any time in the study was significantly inferior $(p=0.0056)$ in vaccinated group (T04) than in control group+ (T03). Like in study 1, a clinically relevant prevented fraction, with a lower 95\% interval >0, was also demonstrated in Study 2.

\subsection{PCV2 Fecal Shedding}

The results of PCV2 fecal shedding detected in studies 1 and 2 are summarized in Figure 2 and Table 3. Before challenge (Day 159) none of the pigs shed PCV2 through the fecal route. In study 1, PCV2a shedding was initially detected four days after challenge (Day 164) and continued until the study completion day (Day 181). From Day 171 through Day 178 , mean fecal shedding was significantly lower $(p \leq 0.0002)$ in vaccinated pigs (T02) when compared to controls (T01). The percentage of positive pigs was also significantly lower $(p=0.0102)$ in vaccinated pigs (T02). A clinically relevant prevented fraction (lower $95 \%$ interval $>0$ ) was also demonstrated. Interestingly on Day 164 vaccinated pigs showed a numerically higher number of copies when compared to the control group. This peak of shedding right after challenge may have explained by the time taken to mount a robust immune response. This response was successfully assembled, and later vaccinated animals showed lower shedding when compared to controls. 


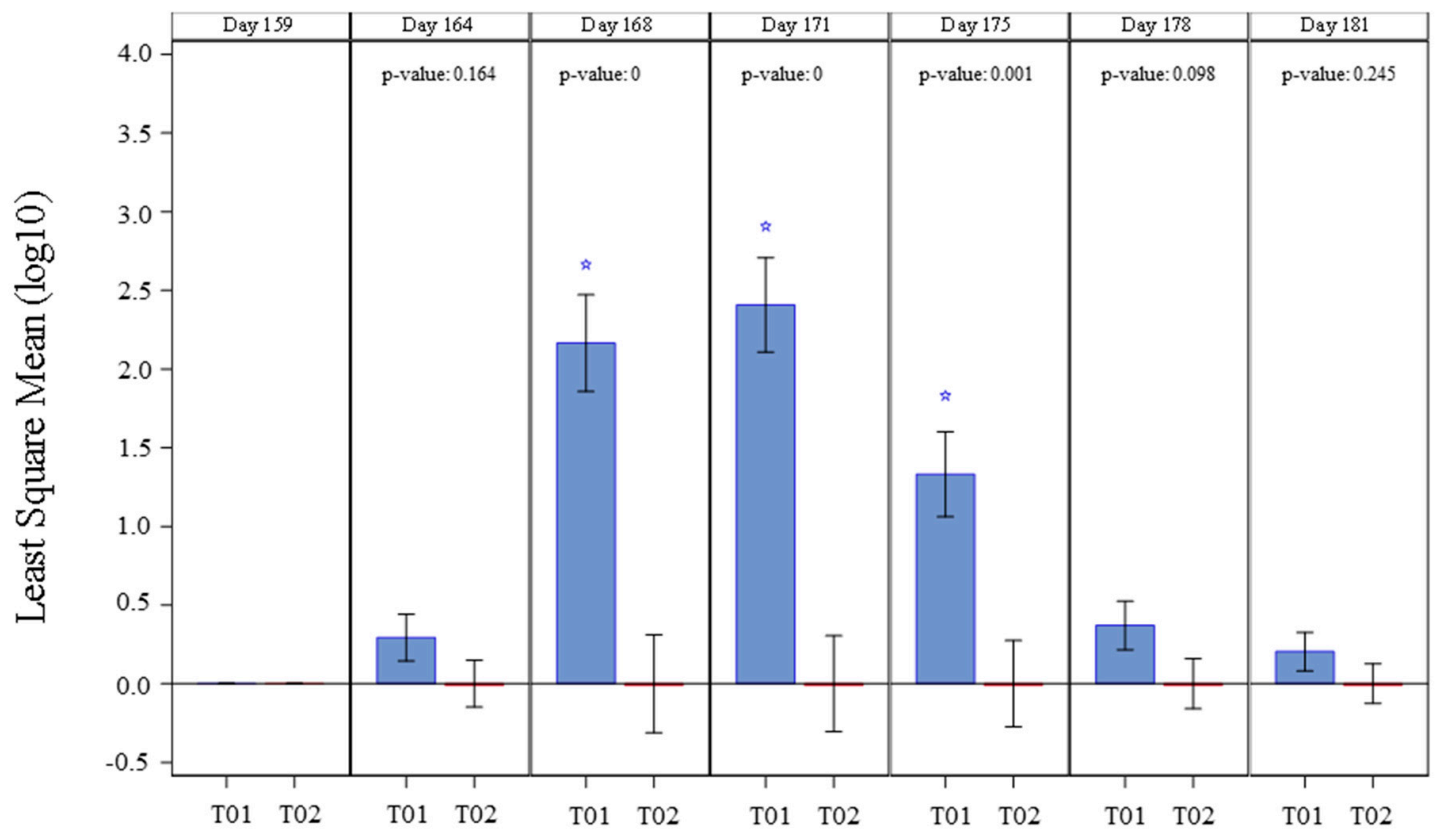

study days

(a)

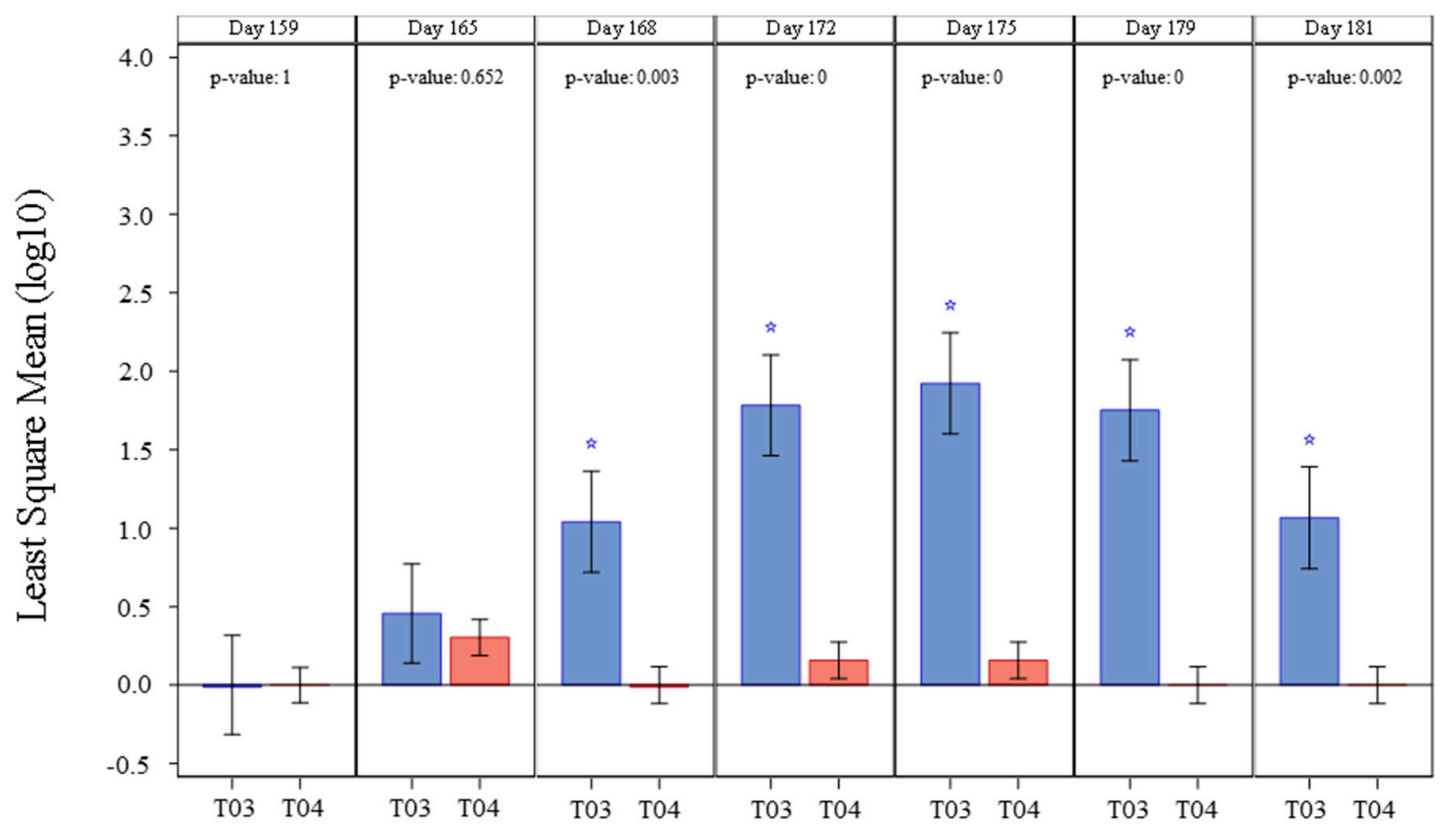

study days

(b)

Figure 1. PCV2 viremia (Least Square Mean $\left(\log _{10}\right)$ of DNA copies/mL) by treatment and day of study and significance: (a) PCV2 viremia detected in study 1, results from T01 are represented in blue and results from T02 are represented in red. When $p$-value $<0.0001$ it is described as 0 , and significant differences between groups $(p \leq 0.05)$ are marked with a blue star; (b) PCV2 viremia detected in study 2, results from T03 are represented in blue and results from T04 are represented in red. When $p$-value $<0.0001$ it is described as 0 , and significant differences between groups $(p \leq 0.05)$ are marked with a blue star. 
Table 2. Percent of ever positive pigs and estimate of prevented fraction for PCV2 viremia.

\begin{tabular}{|c|c|c|c|c|c|c|}
\hline \multirow{2}{*}{ Study } & \multirow[b]{2}{*}{ Treatment } & \multirow{2}{*}{$\begin{array}{l}\text { Number (\%) of q } \\
\text { PCR Positive } \\
\text { Pigs }\end{array}$} & \multirow{2}{*}{$p$-Value } & \multicolumn{3}{|c|}{ Prevented Fraction } \\
\hline & & & & Vs T01 & $\begin{array}{l}\text { Lower 95\% } \\
\text { Bound }\end{array}$ & $\begin{array}{l}\text { Upper } 95 \% \\
\text { Bound }\end{array}$ \\
\hline $\begin{array}{l}\text { Study } 1 \\
\text { (PCV2a) }\end{array}$ & $\begin{array}{c}\text { Control (T01) } \\
\text { Vaccinated (T02) }\end{array}$ & $\begin{array}{c}17 / 28(60.7) \\
0 / 25(0)\end{array}$ & 0.0001 & 1.0000 & 0.7926 & 1.0000 \\
\hline $\begin{array}{l}\text { Study } 2 \\
\text { (PCV2b) }\end{array}$ & $\begin{array}{c}\text { Control (T03) } \\
\text { Vaccinated (T04) }\end{array}$ & $\begin{array}{c}15 / 27(55.6) \\
4 / 26(15.4)\end{array}$ & 0.0056 & 0.72388 & 0.28022 & 0.89408 \\
\hline
\end{tabular}

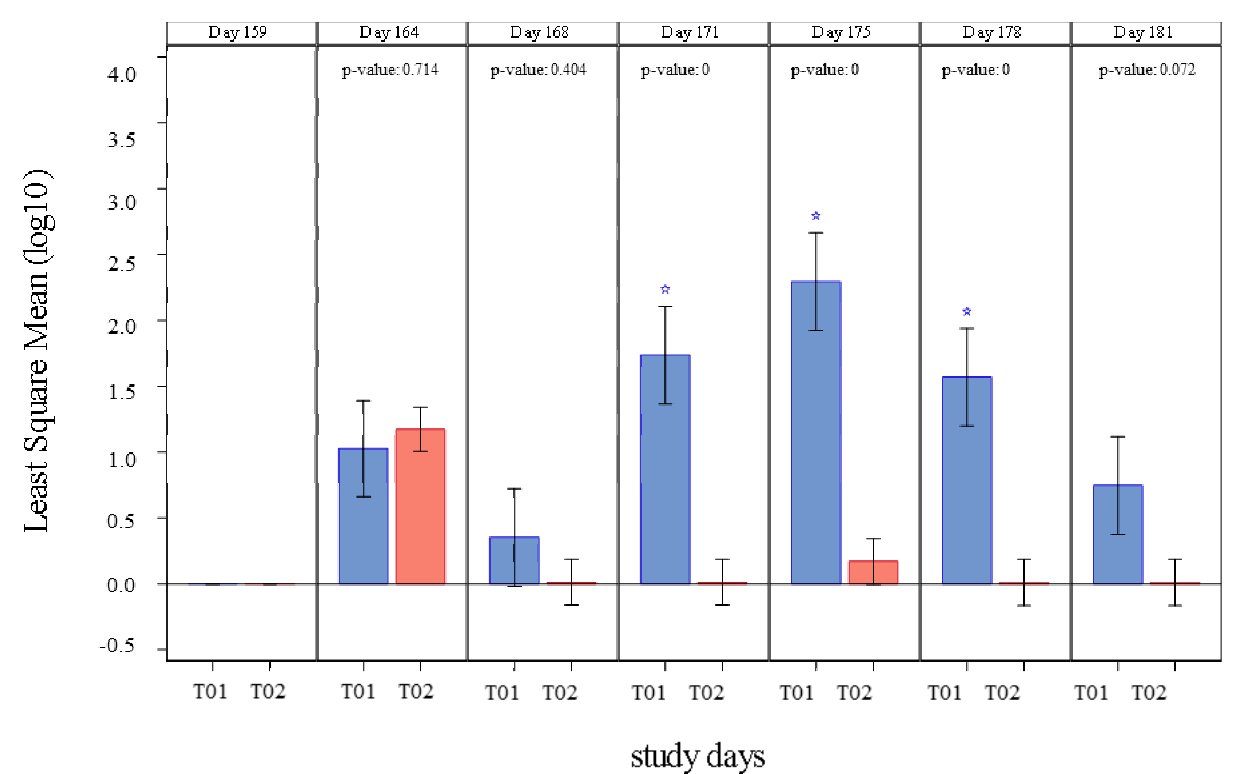

(a)

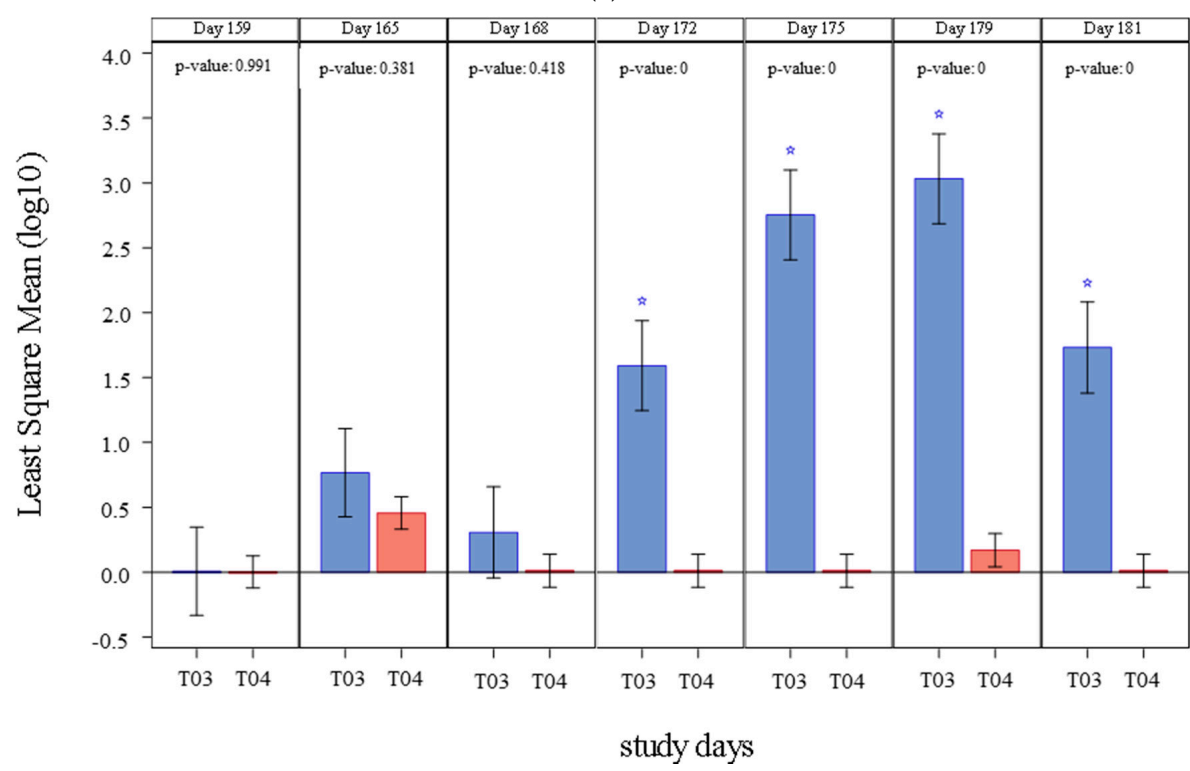

(b)

Figure 2. PCV2 fecal shedding (Least Square Mean $\left(\log _{10}\right)$ of DNA copies $\left./ \mathrm{mL}\right)$ by treatment and day of study and significance: (a) PCV2 fecal shedding detected in study 1, results from T01 are represented in blue and results from T02 are represented in red. When $p$-value $<0.0001$ it is described as 0 , and significant differences between groups $(p \leq 0.05)$ are marked with a blue star; (b) PCV2 fecal shedding detected in study 2, results from T03 are represented in blue and results from T04 are represented in red. When $p$-value $<0.0001$ it is described as 0 , and significant differences between groups ( $p \leq$ 0.05) are marked with a blue star. 
Table 3. Percent of ever positive pigs and estimate of prevented fraction for PCV2 fecal shedding.

\begin{tabular}{|c|c|c|c|c|c|c|}
\hline \multirow[b]{2}{*}{ Study } & \multirow[b]{2}{*}{ Treatment } & \multirow{2}{*}{$\begin{array}{c}\text { Number }(\%) \text { of } \\
\text { q PCR Positive } \\
\text { Pigs }\end{array}$} & \multirow{2}{*}{$p$-Value } & \multicolumn{3}{|c|}{ Prevented Fraction } \\
\hline & & & & Vs Control & $\begin{array}{c}\text { Lower 95\% } \\
\text { Bound }\end{array}$ & $\begin{array}{c}\text { Upper } 95 \% \\
\text { Bound }\end{array}$ \\
\hline $\begin{array}{l}\text { Study } 1 \\
\text { (PCV2a) }\end{array}$ & $\begin{array}{l}\text { Control (T01) } \\
\text { Vaccinated } \\
\text { (T02) }\end{array}$ & $\begin{array}{c}18 / 27(66.7 \%) \\
8 / 27(29.6 \%)\end{array}$ & 0.0102 & 0.56495 & 0.15111 & 0.77703 \\
\hline $\begin{array}{l}\text { Study } 2 \\
\text { (PCV2b) }\end{array}$ & $\begin{array}{l}\text { Control (T03) } \\
\text { Vaccinated } \\
\text { (T04) }\end{array}$ & $\begin{array}{c}21 / 26(80.8 \%) \\
4 / 27(14.8 \%)\end{array}$ & $<0.0001$ & 0.84944 & 0.58637 & 0.94520 \\
\hline
\end{tabular}

In study 2, PCV2 shedding was initially detected five days after challenge (Day 165) and was detected on each timepoint until study completion in control group (T03). Shedding was only detected on Day 165 and Day 179 in vaccinated animals (T04). From Day 172 until Day 181, mean fecal shedding was significantly inferior $(p<0.0001)$ in vaccinates (T04). The percentage of ever positive pigs was significantly less $(p<0.0001)$ in the vaccinated pigs (T04) and a clinically relevant prevented fraction (lower $95 \%$ interval $>0$ ) was also demonstrated.

\subsection{PCV2 Pathological Findings}

Table 4 shows the number of pigs with a positive score on histopathological results for studies 1 and 2 . In study 1 , the percentage of pigs positive for IHC did not show significant differences $(p=0.0515)$ between vaccinated (T02) and control pigs (T01). However, the lower $95 \%$ confidence interval of the prevented fraction was $>0(0.2144)$. The lack of statistical significance in these measures was likely due to the low number of animals positive for PCV2 staining of the lymph node (five in T01 and zero in T02). Differences were also not significant in the percentage of positive pigs among groups for $\operatorname{LD}(p=0.9560)$ or HR $(p=0.4808)$. Regarding the severity of the lesions all lesions described had a score of 1 with the only exception of one control animal that showed a score of 2 on LD in the mesenteric lymph node.

In study 2, the percentage of pigs positive for IHC were significantly lower $(p=0.0098)$ the vaccinated pigs (T04) when compared to controls (T03). The lower 95\% confidence interval of the prevented fraction was $>0$ (0.4256). In addition, the percentage of positive pigs for HR was significantly different based on vaccination status $(p=0.0306)$. On the other hand, differences were not significant for the percentage of pigs positive for LD ( $p$ $=0.0544)$. The lower $95 \%$ confidence interval of the prevented fraction was $<0$ for both variables $(-0.022471$ for $\mathrm{HR}$ and -0.087594 for $\mathrm{LD})$. Regarding the severity of the lesions one vaccinated animal had a score of 2 on HR in the tracheal lymph node, while four control animals showed repeated scores of 2 mainly on HR and LD in most lymph nodes tested.

\subsection{Mhyo Macroscopic Lung Lesions}

Table 5 shows the frequency distributions of total macroscopic lung lesion categories by treatment. Animals belonging to the non-vaccinated control group (T05) did not show any macroscopic lung lesions, indicating that those animals remained free of Mhyo (or other disease which have confounded the interpretation of Mhyo challenge outcome) throughout the pre-challenge study period. At necropsy, the average percentage of lung presenting gross lesions was significantly superior $(p=0.0196)$ in vaccine control animals (T06) when compared to vaccinated (T07) (Table 6). In the vaccine control group (T06) average percentage of lung with lesions was 8.2 while in the vaccinated group (T07) was 4.3. 
Table 4. Results of the histopathological analysis of the different studied lymphoid tissues from vaccinated and control pigs after PCV2 challenge.

Number of Pigs with a Score $>0 /$ Number of Pigs Tested *

\begin{tabular}{|c|c|c|c|c|}
\hline Study & Tissue & Parameter & Control (T01) & Vaccinated (T02) \\
\hline \multirow{12}{*}{$\begin{array}{l}\text { Study } 1 \\
\text { (PCV2a) }\end{array}$} & \multirow{3}{*}{$\begin{array}{c}\text { Mesenteric Lymph } \\
\text { Node }\end{array}$} & $\mathrm{IHC}^{* *}$ & $1 / 27$ & $0 / 25$ \\
\hline & & $\mathrm{LD}^{* * *}$ & $1 / 27$ & $1 / 25$ \\
\hline & & $\mathrm{HR}^{* * * *}$ & $0 / 27$ & $1 / 25$ \\
\hline & \multirow{4}{*}{$\begin{array}{l}\text { Superficial Inguinal } \\
\text { Lymph Node }\end{array}$} & IHC & $4 / 27$ & $0 / 25$ \\
\hline & & LD & $0 / 27$ & $0 / 25$ \\
\hline & & HR & $0 / 27$ & $0 / 25$ \\
\hline & & IHC & $2 / 27$ & $0 / 25$ \\
\hline & \multirow[t]{2}{*}{ Tonsil } & $\mathrm{LD}$ & $0 / 27$ & $0 / 25$ \\
\hline & & HR & $0 / 27$ & $0 / 25$ \\
\hline & \multirow{3}{*}{$\begin{array}{l}\text { Tracheobronchial } \\
\text { Lymph Node }\end{array}$} & IHC & $0 / 27$ & $0 / 25$ \\
\hline & & LD & $0 / 27$ & $0 / 25$ \\
\hline & & HR & $0 / 27$ & $0 / 25$ \\
\hline & & & Control (T03) & Vaccinated (T04) \\
\hline \multirow{12}{*}{$\begin{array}{l}\text { Study } 2 \\
(\mathrm{PCV} 2 \mathrm{~b})\end{array}$} & \multirow{3}{*}{$\begin{array}{c}\text { Mesenteric Lymph } \\
\text { Node }\end{array}$} & IHC & $4 / 25$ & $0 / 26$ \\
\hline & & LD & $6 / 25$ & $2 / 26$ \\
\hline & & HR & $8 / 25$ & $2 / 26$ \\
\hline & \multirow{3}{*}{$\begin{array}{l}\text { Superficial Inguinal } \\
\text { Lymph Node }\end{array}$} & IHC & $1 / 25$ & $0 / 26$ \\
\hline & & LD & $6 / 25$ & $2 / 26$ \\
\hline & & HR & $6 / 25$ & $2 / 26$ \\
\hline & \multirow{3}{*}{ Tonsil } & IHC & $4 / 25$ & $0 / 26$ \\
\hline & & LD & $5 / 25$ & $0 / 26$ \\
\hline & & HR & $3 / 25$ & $0 / 26$ \\
\hline & \multirow{3}{*}{$\begin{array}{l}\text { Tracheobronchial } \\
\text { Lymph Node }\end{array}$} & IHC & $4 / 25$ & $0 / 26$ \\
\hline & & LD & $6 / 25$ & $1 / 26$ \\
\hline & & $\mathrm{HR}$ & $6 / 25$ & $1 / 26$ \\
\hline
\end{tabular}

${ }^{*}$ An animal was considered positive if score $>0 .{ }^{* *}$ IHC: Immunohistochemistry. ${ }^{* * *}$ LD: Lymphoid Depletion. ${ }^{* * * *}$ HR: Histiocytic Replacement.

\subsection{Serology}

In both studies 1 and 2, the mean PCV2 antibodies detected by ELISA declined from vaccination (Day 0) until the day before challenge (Day 159), Figure 3. This drop in antibody levels was more acute in control groups (T01 and T03) compared to vaccinates and was significantly lower when compared to vaccinated pigs (T02 and T04) on Day 159 ( $p=0.0005$ on study 1 and $p<0.0001$ on study 2, respectively). From Day 159 until study completion, antibody levels increased in all treatment groups in both studies. However, vaccinated animals (T02 and T04) continued having significantly higher antibody values $p<0.0001$ in study 1 and $p<0.0001$ in study 2, respectively, when compared to controls (T01 and T03). 
Table 5. Frequency distributions of total Mhyo-like macroscopic lung lesion categories by treatment.

\begin{tabular}{|c|c|c|c|c|c|c|c|c|c|c|c|}
\hline \multirow{3}{*}{ Treatment } & \multicolumn{10}{|c|}{ Lung Lesion Category } & \multirow{3}{*}{$\begin{array}{c}\begin{array}{c}\text { Total } \\
\text { Observations }\end{array} \\
\text { Number } \\
\end{array}$} \\
\hline & \multicolumn{2}{|c|}{$0 \% \leq$ to $<5 \%$} & \multicolumn{2}{|c|}{$5 \% \leq$ to $<10 \%$} & \multicolumn{2}{|c|}{$10 \% \leq$ to $<20 \%$} & \multicolumn{2}{|c|}{$20 \% \leq$ to $<30 \%$} & \multicolumn{2}{|c|}{$30 \% \leq \%$} & \\
\hline & Number & $\%$ & Number & $\%$ & Number & $\%$ & Number & $\%$ & Number & $\%$ & \\
\hline $\begin{array}{c}\text { Non- } \\
\text { vaccinated } \\
\text { control (T05) }\end{array}$ & 9 & 100.0 & 0 & 0.0 & 0 & 0.0 & 0 & 0.0 & 0 & 0.0 & 9 \\
\hline Control (T06) & 26 & 37.1 & 10 & 14.3 & 18 & 25.7 & 10 & 14.3 & 6 & 8.6 & 70 \\
\hline $\begin{array}{l}\text { Vaccinated } \\
\text { (T07) }\end{array}$ & 37 & 55.2 & 10 & 14.9 & 9 & 13.4 & 8 & 11.9 & 3 & 4.5 & 67 \\
\hline
\end{tabular}

Table 6. Least squares means and significance values for Mhyo-consistent macroscopic lung lesions.

\begin{tabular}{|c|c|c|c|c|c|}
\hline \multirow[b]{2}{*}{ Treatment } & \multicolumn{4}{|c|}{ Summary of Least Squares Means ${ }^{1}$} & \multirow{2}{*}{$\begin{array}{c}\text { Contrast vs. T06 } \\
p \text {-Value }\end{array}$} \\
\hline & Number of Animals & Mean \% Lung with Lesions & $\begin{array}{l}\text { Std Deviaton/Std Error }{ }^{2} \% \\
\text { Lung with Lesions }\end{array}$ & Range \% Lung with Lesions & \\
\hline & 5 (Day 84) & 0.0 & 0.00 & 0.0 to 0.0 & $\mathrm{Na}^{3}$ \\
\hline Non-vaccinated control (105) & 4 (Day 159) & 0.0 & 0.00 & 0.0 to 0.0 & $\mathrm{Na}$ \\
\hline Control (T06) & 70 & 8.2 & 1.45 & 0.0 to 45.0 & $\mathrm{Na}$ \\
\hline Vaccinated (T07) & 67 & 4.3 & 1.09 & 0.0 to 35.0 & 0.0196 \\
\hline
\end{tabular}

${ }^{1}$ Back Transformed Least Squares; ${ }^{2}$ Standard Deviation for T05, Standard Error for T06 and T07; ${ }^{3}$ Not available 


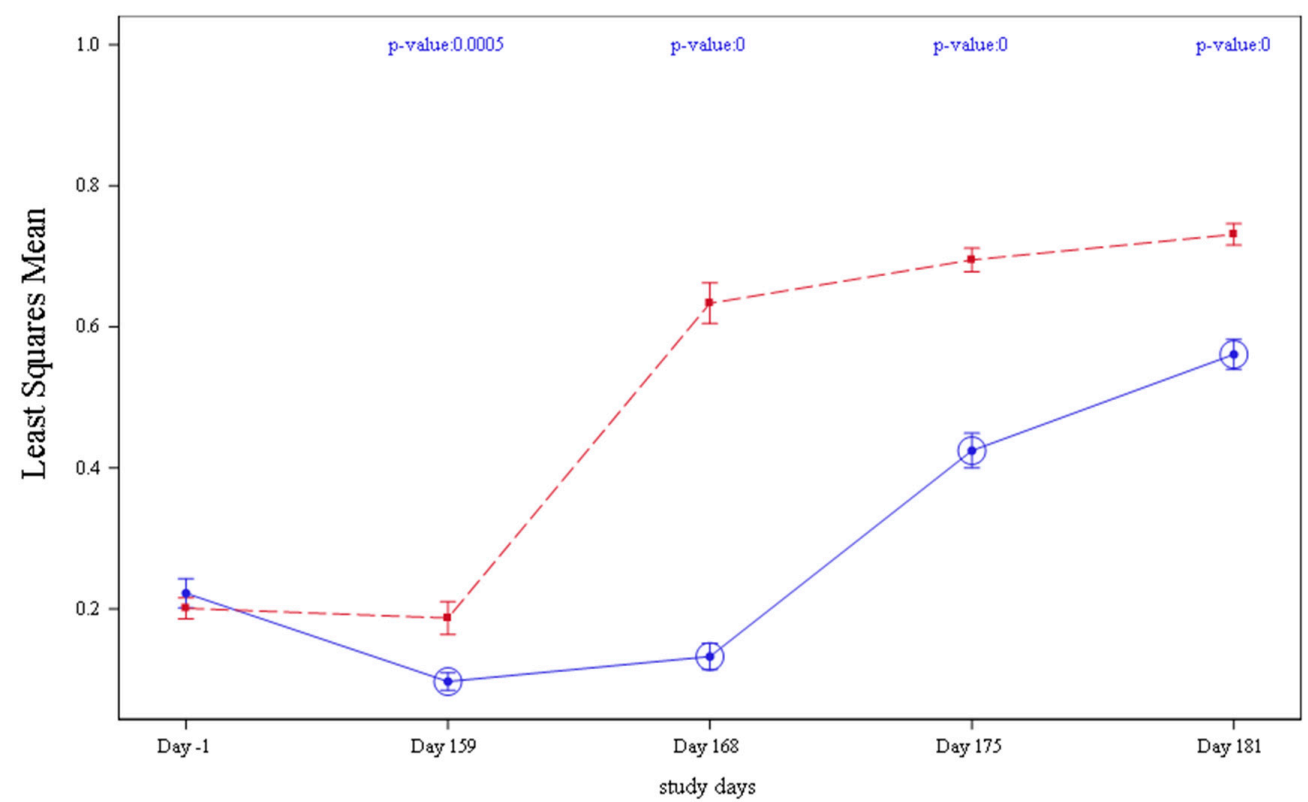

(a)

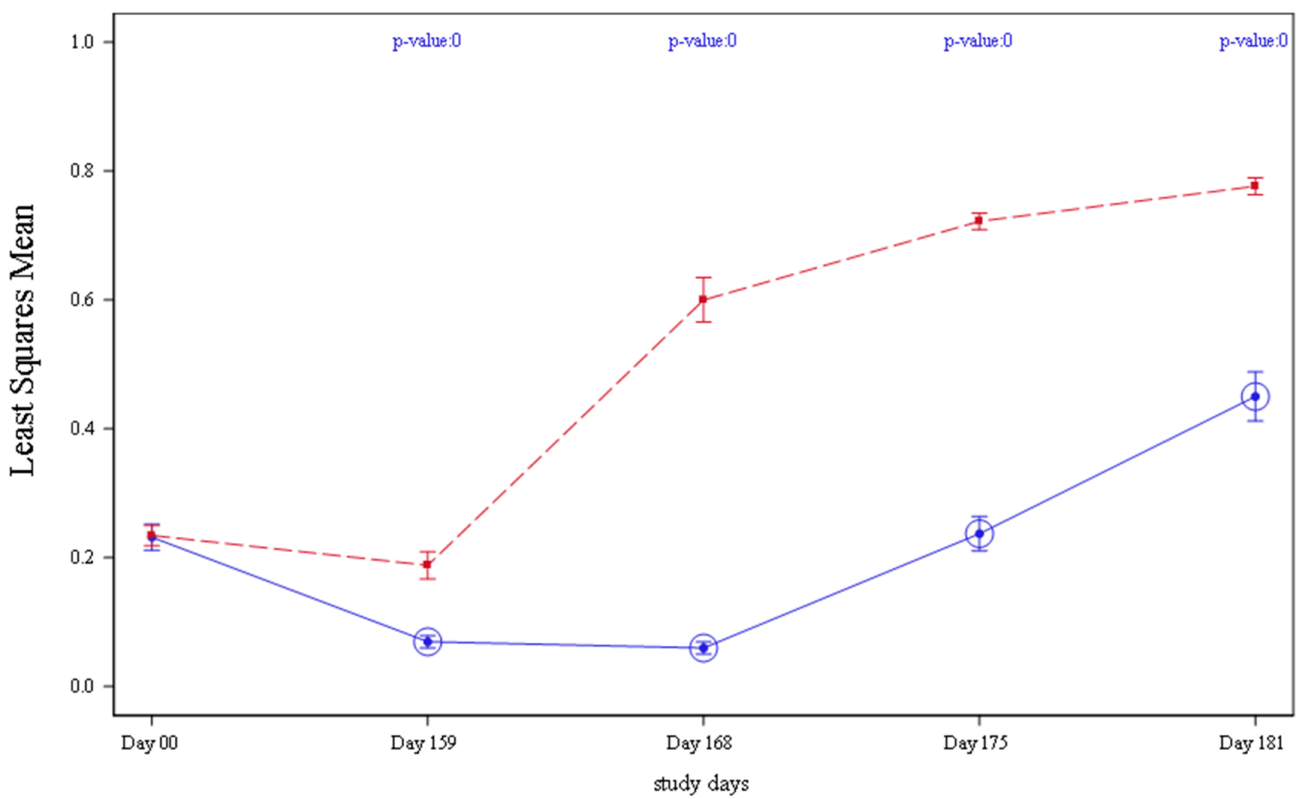

(b)

Figure 3. PCV2 serology (Least Squares Mean) by treatment and day of study and significance values: (a) PCV2 serology detected on study 1, results from T01 are represented in blue and results T02. are represented in red, when $p$-value $<0.0001$ it was represented as 0; (b) PCV2 serology detected on study 2, results from T03 are represented in blue and results from T04 are represented in red, when $p$-value $<0.0001$ it was represented as 0 .

All pigs in study 3 were negative for Mhyo-specific antibodies by a competitive ELISA prior to vaccination (Table 7). Prior to challenge (Day 159), all non-vaccinated control group (T05) and vaccine control group (T06) pigs remained Mhyo antibody negative. Before challenge (Day 159) and at necropsy (Day 187/188), the vaccinated group (T07) had significantly higher ELISA levels $(p \leq 0.0068)$ in comparison to the vaccine control group (T06). 
Table 7. Mhyo serology (Least Squares Means, Standard Errors and Significance values) per treatment and day of study.

\begin{tabular}{|c|c|c|c|c|}
\hline \multicolumn{2}{|c|}{ Treatment } & \multirow{2}{*}{$\begin{array}{l}\text { Day -1 } \\
98.7941\end{array}$} & \multirow{2}{*}{$\begin{array}{l}\text { Day } 159 \\
78.0069\end{array}$} & \multirow{2}{*}{$\begin{array}{c}\text { Day 187/188 } \\
51.8656\end{array}$} \\
\hline & $\begin{array}{c}\text { Geometric Least Squares } \\
\text { Mean }\end{array}$ & & & \\
\hline Control (T06) & Number of observations & 71 & 70 & 70 \\
\hline \multirow{4}{*}{ Vaccinated (T07) } & Standard Errors & 1.5117 & 1.4927 & 3.1159 \\
\hline & $\begin{array}{c}\text { Geometric Least Squares } \\
\text { Mean }\end{array}$ & 98.8315 & 72.9733 & 27.7770 \\
\hline & Number of observations & 71 & 68 & 67 \\
\hline & Standard Errors & 1.5434 & 1.7582 & 3.9046 \\
\hline \multicolumn{2}{|c|}{ Significance vs. T06 } & $p=0.9735$ & $p=0.0068$ & $p \leq 0.0001$ \\
\hline
\end{tabular}

\subsection{Body Weights}

Body weights were collected for vaccine control (T06) and vaccinated (T07) groups in study 3. Differences in mean weights were not significant $(p>0.05)$ between any of the treatment groups was described on any time (Table 8).

Table 8. Least squares means and significance values for body weights.

\begin{tabular}{cccc}
\hline \multirow{2}{*}{ Treatment } & \multicolumn{3}{c}{ Least Squares Mean $\mathbf{( k g )}$} \\
\cline { 2 - 4 } & Day $\mathbf{- 1}$ & Day 159 & Day 187/188 \\
\hline Control (T06) & 5.1 & 116.6 & 130.4 \\
Vaccinated (T07) & 5.2 & 116.0 & 128.4 \\
Significance vs. T06 & $p=0.6796$ & $p=0.8298$ & $p=0.4945$ \\
\hline
\end{tabular}

\subsection{Clinical Signs}

In study 1, five control (T01) and seven vaccinated animals (T02) showed clinical signs after challenge. Those clinical signs were in all cases related with problems in claws or limbs. Regarding the adverse events one animal from the control group (T01) was found death prior to challenge on day 109 of study. Necropsy showed diffuse pericarditis, peritonitis, mild pleuritis, and less than $10 \%$ lung consolidation. Bacterial analysis was positive for mixed bacteria and E. coli from the peritoneum and pericardium. Six additional animals were withdrawn from the study after challenge, between Days 161 and 175 (five from the vaccinated group (T02) and one from the control group (T01), due to lameness second to abraded or torn claws. Those six animals were omitted from the tissue analysis and three out of those six were omitted from PCV2 viremia and shedding analysis as they were treated with antibiotics during the study. Three additional animals treated with antibiotics during the study were omitted from viremia and shedding analysis.

In study 2, two control (T03) and three vaccinated animals (T04) showed clinical signs after challenge. Those clinical signs were in all cases related with problems in claws or limbs. Regarding the adverse events one animal from the control group (T03) was found death prior to challenge on day 91 of study. Necropsy showed edematous hemorrhagic lungs. Seven animals (four belonging to the vaccinated group (T04) and three controls (T03)) were withdrawn from the study, three before challenge and the remaining four after challenge, between Days 162 and 179 due to lameness second to abraded or torn claws. Those seven animals were omitted from tissue analysis and four were also omitted from PCV2 viremia and shedding analysis as they were treated with antibiotics during the study.

In study 3, one animal from the non-treated control group (T05), one animal from the vaccinated control (T06), and three animals from the vaccinated group (T07) were found dead prior to challenge. Necropsies suggested meningitis due to Strep. suis in the T05 pig; severe peritonitis, arthritis in one leg and torsion of elongated mesentery in the three pigs from T07. The T06 animal that died was found stuck between the fence and the waterer. In addition, one animal from the vaccinated group (T07) died after challenge. Necropsy revealed presence of fluid in the abdomen and thoracic cavity; bacterial culture from the fluid sample resulted in isolation of $H$. parasuis. 


\section{Discussion}

The goal of this study was to assess the efficacy of a novel ready-to-use vaccine including PCV2a, PCV2b, and Mhyo, after one dose of intramuscular administration to pigs at $21 \pm 4$ days of age, against a pathogenic challenge 23 weeks after vaccination. With that aim, three independent studies were performed, each study evaluating one of the fractions included in the vaccine. Vaccination with PCVa-PCV2b-Mhyo significantly protected animals from PCV2 associated disease as well as respiratory disease caused by Mhyo.

PCV2 and Mhyo are both critical respiratory pathogens in swine. Piglet vaccination around three weeks of age, corresponding with weaning and pig handling, is one of the main strategies to control both pathogens during the nursery and fattening periods [20]. Combined application of PCV2 and Mhyo vaccines suppose an advantage for farmers and veterinarians in terms of economizing pig handling events and associated management/labor costs. Importantly, administration of a multi-valent PCV2-Mhyo vaccination is beneficial for animal welfare. The first commercial approach to combine both PCV2 and Mhyo vaccines in one dose consisted in the combination of two already licensed products from the same manufacturer [27]. Soon, this ready-to-mix vaccine evolved to the development and commercialization of ready-to-use products [28]. In addition to the benefits derived from the combined multivalent application, the ability of vaccines to confer durable and stable protection is a key asset. In intensive pig production the average fattening time is around six months. Thus, vaccines with a DOI close to this time period suppose a clear advantage as they are able to confer protection during the entire fattening period.

This vaccine includes both a PCV2a and a PCV2b fraction in a single bottle. Most PCV2 vaccines in the market are based on PCV2a technology only and all (with the exception of the current formulation) include a single genotype. PCV2a based vaccines have been a success story for the swine industry and the vast majority of pigs are vaccinated against PCV2 worldwide. Despite vaccine use and the ensuing benefit to swine in terms of reduced occurrence and severity in clinical signs, PCV2 seroprevalence continues with some herds still reporting clinical PCV2. In addition to vaccine failures associated with clinical disease, subclinical PCV2 infection remains a major problem for economic loss even for herds that vaccinate [29].

While PCV2a vaccines have been demonstrated to generate some cross-protection from clinical PCV2, associated disease PCV2 viruses continue to evolve and instances of vaccine failures due to diverse PCV2 field virus challenge have been documented [30]. PCV2 vaccines generally do not provide sterilizing immunity $[30,31]$ and historic single genotype PCV2 vaccines may not induce broad enough cross-protection to cover evolving field viruses [32]. In fact, traditional single genotype PCV2 vaccine use has contributed to the selection of emergent viruses [33]. Emergent field viruses are especially different from vaccine strains in capsid epitopic regions $[30,31]$. Since the capsid is the immunodominant protein, shifts away from vaccine capsid epitopes may be contributing the vaccine failures. It is noteworthy that traditional PCV2a vaccines have clearly added to the selection of PCV2a field viruses and less to the selection and diversity of PCV2b and PCV2d viruses [33-36]. This may reasonably imply that PCV2 vaccine induced coverage is best when the vaccine virus and challenge virus are closely matched.

PCV2b and PCV2d have surpassed PCV2a in terms of prevalence in many geographies and new PCV2 genotypes including those with recombinant virus origins are continually discovered [6]. Importantly, all three, PCV2a, PCV2b, and PCV2d, continue to circulate. Studies of PCV2 phylogeny suggest two major groups of PCV2, namely, the PCV2a and $\mathrm{PCV} 2 \mathrm{~b} / \mathrm{d}$ genogroups [37]. This is reasonable as PCV2b and $2 \mathrm{~d}$ share more common epitopes with each other than PCV2a shares with PCV2d [26,38,39]. Taken together, having a vaccine which contains both PCV2a and PCV2b, increases the total number of epitopes in the vaccine. Thus, the PCV2a-PCV2b vaccine has the potential to educate the pig's immune system to diverse PCV2 viruses including these three disease-causing circulation strains.

In most markets around the world, pigs are slaughtered around 26 weeks of age. Considering that the vaccine evaluated here was administered at three weeks of age, 
the challenge date, 23 weeks (Day 159), was selected to ensure that the vaccine confers protection during the entire fattening period. Other swine vaccines available in the market target similar duration of immunity period when dosed at three weeks. However, none of them reached a duration of immunity longer than 23 weeks for both the PCV2 and the Mhyo fractions, when administered, combined and as a single dose to three weeks old pigs [40-44]

Protective efficacy in studies 1 and 2 is evidenced by fewer percent of animals ever viremic, and fewer percent of animals ever fecal shedding following a challenge. Although fewer percent of animals were positive for IHC, LD, or HR; differences were not significative. This may have been explained by the low amount of pigs with pathological changes and abnormal clinical signs after challenge in both groups. Similar PCV2 subclinical infection outcome has been previously described in PCV2 experimental inoculations which is consequent to that described in previous PCV2 experimental infections [24,45]. Finally, criteria for prevention/reduction in viremia, fecal shedding, and PCV2 antigen in lymphoid tissues (IHC) were met as those variables presented a value $>0$ on the lower $95 \%$ confidence interval for the prevented fraction.

Study 3 was also considered as valid as animals did not have pre-challenge exposure to Mhyo. The experimental model used for infection was based on that described in previous studies including the same challenge strain [24,40]. This challenge demonstrated to be valid as the back-transformed mean lung lesion scores observed in control pigs (T06) was greater than 3\%. Vaccination significantly protected animals from Mhyo infection as evidenced by the significantly lower percentage of lung lesions detected in vaccinated pigs (T07) following challenge. In addition, vaccinated pigs (T07) showed significantly higher level of antibodies at necropsy, when compared to control pigs (T06). Although vaccination did not have any impact in the body weights of the animals it can be concluded that vaccination was efficacious in building up a stronger antibody response and preventing lung lesions at necropsy.

\section{Conclusions}

The efficacy of one dose of the three fractions included in the vaccine (PCV2a/PCV2b/Mhyo) against a virulent challenge at 23 weeks was verified by an enhancement in virological/ bacteriological, immunological, and clinical variables. Therefore, a DOI of at least 23 weeks was demonstrated for each of the three components of the trivalent vaccine tested.

Author Contributions: M.S., M.B. (Meggan Bandrick) and L.T. designed the study. M.S. and M.B. (Meggan Bandrick) coordinated the study execution, sample processing, and analyzed the results. L.T. designed and performed the statistical analysis. J.C.M.G. drafted the original manuscript. M.S., M.B. (Meggan Bandrick), L.T., and M.B. (Mónica Balasch) revised the manuscript. All authors have read and agreed to the published version of the manuscript.

Funding: This research was funded by Zoetis.

Institutional Review Board Statement: The study was conducted according to the guidelines of the Declaration of Helsinki, and approved by the Zoetis Institutional Animal Care and Use Committee, and by IACUC of the participating study sites (protocol code studies 1 and 2, \# KZ-3087e-2014-10-tkh; approved on the 19 June 2015 and study 3, 17-NARDO-04 approved on the 7 November 2017).

Informed Consent Statement: Not applicable.

Data Availability Statement: Data is contained within the article.

Acknowledgments: The authors would like to acknowledge the University of Minnesota, Veterinary Diagnostic Laboratory (UMN-VDL), and Iowa State University, Veterinary Diagnostic Laboratory, for their support with the serological and histopathological analysis of the samples.

Conflicts of Interest: All the authors were Zoetis employees at the time of publication. 


\section{References}

1. Chae, C. Porcine respiratory disease complex: Interaction of vaccination and porcine circovirus type 2, porcine reproductive and respiratory syndrome virus, and Mycoplasma hyopneumoniae. Vet. J. 2016, 212, 1-6. [CrossRef]

2. Allan, G.M.; McNeilly, F.; Kennedy, S.; Daft, B.; Clarke, E.G.; Ellis, J.A.; Haines, D.M.; Meehan, B.M.; Adair, B.M. Isolation of porcine circovirus-like viruses from pigs with a wasting disease in the USA and Europe. J. Vet. Diagn. Investig. 1998, 10, 3-10. [CrossRef] [PubMed]

3. Gillespie, J.; Opriessnig, T.; Meng, X.J.; Pelzer, K.; Buechner-Maxwell, V. Porcine circovirus type 2 and porcine circovirus-associated disease. J. Vet. Intern. Med. 2009, 23, 1151-1163. [CrossRef] [PubMed]

4. Correa-Fiz, F.; Franzo, G.; Llorens, A.; Huerta, E.; Sibila, M.; Kekarainen, T.; Segales, J. Porcine circovirus 2 (PCV2) population study in experimentally infected pigs developing PCV2-systemic disease or a subclinical infection. Sci. Rep. 2020, $10,17747$. [CrossRef] [PubMed]

5. Bao, F.; Mi, S.; Luo, Q.; Guo, H.; Tu, C.; Zhu, G.; Gong, W. Retrospective study of porcine circovirus type 2 infection reveals a novel genotype PCV2f. Transbound. Emerg. Dis. 2018, 65, 432-440. [CrossRef]

6. Franzo, G.; Segales, J. Porcine circovirus 2 (PCV-2) genotype update and proposal of a new genotyping methodology. PLoS ONE 2018, 13, e0208585. [CrossRef]

7. Firth, C.; Charleston, M.A.; Duffy, S.; Shapiro, B.; Holmes, E.C. Insights into the evolutionary history of an emerging livestock pathogen: Porcine circovirus 2. J. Virol. 2009, 83, 12813-12821. [CrossRef] [PubMed]

8. Beach, N.M.; Meng, X.J. Efficacy and future prospects of commercially available and experimental vaccines against porcine circovirus type 2 (PCV2). Virus Res. 2012, 164, 33-42. [CrossRef]

9. Gagnon, C.A.; Tremblay, D.; Tijssen, P.; Venne, M.H.; Houde, A.; Elahi, S.M. The emergence of porcine circovirus 2b genotype (PCV-2b) in swine in Canada. Can. Vet. J. 2007, 48, 811-819.

10. Cheung, A.K.; Lager, K.M.; Kohutyuk, O.I.; Vincent, A.L.; Henry, S.C.; Baker, R.B.; Rowland, R.R.; Dunham, A.G. Detection of two porcine circovirus type 2 genotypic groups in United States swine herds. Arch. Virol. 2007, 152, 1035-1044. [CrossRef]

11. Cortey, M.; Pileri, E.; Sibila, M.; Pujols, J.; Balasch, M.; Plana, J.; Segales, J. Genotypic shift of porcine circovirus type 2 from PCV-2a to PCV-2b in Spain from 1985 to 2008. Vet. J. 2011, 187, 363-368. [CrossRef]

12. Dupont, K.; Nielsen, E.O.; Baekbo, P.; Larsen, L.E. Genomic analysis of PCV2 isolates from Danish archives and a current PMWS case-control study supports a shift in genotypes with time. Vet. Microbiol. 2008, 128, 56-64. [CrossRef] [PubMed]

13. Wang, F.; Guo, X.; Ge, X.; Wang, Z.; Chen, Y.; Cha, Z.; Yang, H. Genetic variation analysis of Chinese strains of porcine circovirus type 2. Virus Res. 2009, 145, 151-156. [CrossRef] [PubMed]

14. Guo, L.; Fu, Y.; Wang, Y.; Lu, Y.; Wei, Y.; Tang, Q.; Fan, P.; Liu, J.; Zhang, L.; Zhang, F.; et al. A porcine circovirus type 2 (PCV2) mutant with 234 amino acids in capsid protein showed more virulence in vivo, compared with classical PCV2a/b strain. PLoS ONE 2012, 7, e41463. [CrossRef]

15. Xiao, C.T.; Harmon, K.M.; Halbur, P.G.; Opriessnig, T. PCV2d-2 is the predominant type of PCV2 DNA in pig samples collected in the U.S. during 2014-2016. Vet. Microbiol. 2016, 197, 72-77. [CrossRef]

16. Maes, D.; Segales, J.; Meyns, T.; Sibila, M.; Pieters, M.; Haesebrouck, F. Control of Mycoplasma hyopneumoniae infections in pigs. Vet. Microbiol. 2008, 126, 297-309. [CrossRef] [PubMed]

17. Sibila, M.; Pieters, M.; Molitor, T.; Maes, D.; Haesebrouck, F.; Segales, J. Current perspectives on the diagnosis and epidemiology of Mycoplasma hyopneumoniae infection. Vet. J. 2009, 181, 221-231. [CrossRef]

18. Opriessnig, T.; Gimenez-Lirola, L.G.; Halbur, P.G. Polymicrobial respiratory disease in pigs. Anim. Health Res. Rev. 2011, 12, 133-148. [CrossRef]

19. Afghah, Z.; Webb, B.; Meng, X.J.; Ramamoorthy, S. Ten years of PCV2 vaccines and vaccination: Is eradication a possibility? Vet. Microbiol. 2017, 206, 21-28. [CrossRef]

20. Segales, J. Best practice and future challenges for vaccination against porcine circovirus type 2. Expert Rev. Vaccines 2015, 14, 473-487. [CrossRef]

21. Madson, D.M.; Patterson, A.R.; Ramamoorthy, S.; Pal, N.; Meng, X.J.; Opriessnig, T. Effect of porcine circovirus type 2 (PCV2) vaccination of the dam on PCV2 replication in utero. Clin. Vaccine Immunol. 2009, 16, 830-834. [CrossRef] [PubMed]

22. Opriessnig, T.; Gerber, P.F.; Xiao, C.T.; Halbur, P.G.; Matzinger, S.R.; Meng, X.J. Commercial PCV2a-based vaccines are effective in protecting naturally PCV2b-infected finisher pigs against experimental challenge with a 2012 mutant PCV2. Vaccine 2014, 32, 4342-4348. [CrossRef]

23. Maes, D.; Sibila, M.; Kuhnert, P.; Segales, J.; Haesebrouck, F.; Pieters, M. Update on Mycoplasma hyopneumoniae infections in pigs: Knowledge gaps for improved disease control. Transbound. Emerg. Dis. 2018, 65 (Suppl. 1), 110-124. [CrossRef]

24. Sibila, M.; Guevara, G.; Cuadrado, R.; Pleguezuelos, P.; Perez, D.; Perez de Rozas, A.; Huerta, E.; Llorens, A.; Valero, O.; Perez, M.; et al. Comparison of Mycoplasma hyopneumoniae and porcine circovirus 2 commercial vaccines efficacy when applied separate or combined under experimental conditions. Porcine Health Manag. 2020, 6, 11. [CrossRef]

25. Sorden, S.D.; Harms, P.A.; Nawagitgul, P.; Cavanaugh, D.; Paul, P.S. Development of a polyclonal-antibody-based immunohistochemical method for the detection of type 2 porcine circovirus in formalin-fixed, paraffin-embedded tissue. J. Vet. Diagn. Investig. 1999, 11, 528-530. [CrossRef] 
26. Kurtz, S.; Grau-Roma, L.; Cortey, M.; Fort, M.; Rodriguez, F.; Sibila, M.; Segales, J. Pigs naturally exposed to porcine circovirus type 2 (PCV2) generate antibody responses capable to neutralise PCV2 isolates of different genotypes and geographic origins. Vet. Res. 2014, 45, 29. [CrossRef] [PubMed]

27. Hernandez-Caravaca, I.; Gourgues, S.F.; Rodriguez, V.; Estrada, E.D.; Ceron, J.J.; Escribano, D. Serum acute phase response induced by different vaccination protocols against circovirus type 2 and Mycoplasma hyopneumoniae in piglets. Res. Vet. Sci. 2017, 114, 69-73. [CrossRef]

28. Pagot, E.; Rigaut, M.; Roudaut, D.; Panzavolta, L.; Jolie, R.; Duivon, D. Field efficacy of Porcilis(R) PCV M Hyo versus a licensed commercially available vaccine and placebo in the prevention of PRDC in pigs on a French farm: A randomized controlled trial. Porcine Health Manag. 2017, 3, 3. [CrossRef] [PubMed]

29. Alarcon, P.; Rushton, J.; Nathues, H.; Wieland, B. Economic efficiency analysis of different strategies to control post-weaning multi-systemic wasting syndrome and porcine circovirus type 2 subclinical infection in 3-weekly batch system farms. Prev. Vet. Med. 2013, 110, 103-118. [CrossRef]

30. Gava, D.; Serrao, V.H.B.; Fernandes, L.T.; Cantao, M.E.; Ciacci-Zanella, J.R.; Mores, N.; Schaefer, R. Structure analysis of capsid protein of Porcine circovirus type 2 from pigs with systemic disease. Braz. J. Microbiol. 2018, 49, 351-357. [CrossRef]

31. Saha, D.; Huang, L.; Bussalleu, E.; Lefebvre, D.J.; Fort, M.; Van Doorsselaere, J.; Nauwynck, H.J. Antigenic subtyping and epitopes' competition analysis of porcine circovirus type 2 using monoclonal antibodies. Vet. Microbiol. 2012, 157, 13-22. [CrossRef]

32. Karuppannan, A.K.; Opriessnig, T. Porcine Circovirus Type 2 (PCV2) Vaccines in the Context of Current Molecular Epidemiology. Viruses 2017, 9, 99. [CrossRef]

33. Franzo, G.; Cortey, M.; Segales, J.; Hughes, J.; Drigo, M. Phylodynamic analysis of porcine circovirus type 2 reveals global waves of emerging genotypes and the circulation of recombinant forms. Mol. Phylogenet. Evol. 2016, 100, 269-280. [CrossRef]

34. Ssemadaali, M.A.; Ilha, M.; Ramamoorthy, S. Genetic diversity of porcine circovirus type 2 and implications for detection and control. Res. Vet. Sci. 2015, 103, 179-186. [CrossRef]

35. Kekarainen, T.; Gonzalez, A.; Llorens, A.; Segales, J. Genetic variability of porcine circovirus 2 in vaccinating and non-vaccinating commercial farms. J. Gen. Virol. 2014, 95, 1734-1742. [CrossRef]

36. Reiner, G.; Hofmeister, R.; Willems, H. Genetic variability of porcine circovirus 2 (PCV2) field isolates from vaccinated and non-vaccinated pig herds in Germany. Vet. Microbiol. 2015, 180, 41-48. [CrossRef]

37. Bandrick, M.; Gutierrez, A.H.; Desai, P.; Rincon, G.; Martin, W.D.; Terry, F.E.; De Groot, A.S.; Foss, D.L. T cell epitope content comparison (EpiCC) analysis demonstrates a bivalent PCV2 vaccine has greater T cell epitope overlap with field strains than monovalent PCV2 vaccines. Vet. Immunol. Immunopathol. 2020, 223, 110034. [CrossRef]

38. Constans, M.; Ssemadaali, M.; Kolyvushko, O.; Ramamoorthy, S. Antigenic Determinants of Possible Vaccine Escape by Porcine Circovirus Subtype 2b Viruses. Bioinform. Biol. Insights 2015, 9, 1-12. [CrossRef] [PubMed]

39. Saha, D.; Lefebvre, D.J.; Ooms, K.; Huang, L.; Delputte, P.L.; Van Doorsselaere, J.; Nauwynck, H.J. Single amino acid mutations in the capsid switch the neutralization phenotype of porcine circovirus 2. J. Gen. Virol. 2012, 93, 1548-1555. [CrossRef] [PubMed]

40. Porcilis PCV M Hyo. Available online: https://www.ema.europa.eu/en/documents/product-information/porcilis-pcv-mhyoepar-product-information_en.pdf (accessed on 16 July 2021).

41. Suvaxyn Circo+MH RTU. Available online: https:/ / www.ema.europa.eu/en/documents/product-information/suvaxyncircomhrtu-epar-product-information_en.pdf (accessed on 16 July 2021).

42. Circovac. Available online: https://www.ema.europa.eu/en/documents/product-information/circovac-epar-productinformation_en.pdf (accessed on 16 July 2021).

43. Ingelvac Circoflex. Available online: https://www.ema.europa.eu/en/documents/product-information/ingelvac-circoflexepar-product-information_en.pdf (accessed on 16 July 2021).

44. Myosphere PCV ID. Available online: https://www.ema.europa.eu/en/documents/product-information/mhyosphere-pcv-idepar-product-information_en.pdf (accessed on 16 July 2021).

45. Sibila, M.; Fort, M.; Nofrarias, M.; Perez de Rozas, A.; Galindo-Cardiel, I.; Mateu, E.; Segales, J. Simultaneous porcine circovirus type 2 and Mycoplasma hyopneumoniae co-inoculation does not potentiate disease in conventional pigs. J. Comp. Pathol. 2012, 147, 285-295. [CrossRef] [PubMed] 